\title{
Metapragmatic stereotypes and humour: interpreting and perceiving linguistic homogeneity in mass culture texts
}

\author{
Vasia Tsami \\ University of Crete \\ tsamibasil@gmail.com
}

\begin{abstract}
The present study concentrates on the potential of mass culture texts to impose specific metapragmatic stereotypes (Agha 2007) through humour on the wider audience. Metapragmatic stereotypes constitute speakers' internalized models of how language should or should not be used; such models guide speakers' own language use and enable them to make evaluations about their own language behaviour or that of others. In this context, I explore the dominant metapragmatic stereotypes for the interpretation and perception of humorous mass culture texts. To this end, I analyse a humorous Greek TV advertisement of a telecommunications company. Drawing upon Coupland's (2007) conceptualization of style and the General Theory of Verbal Humour (Attardo 2001), I intend to show that humour reflects, sustains, and reproduces the dominant metapragmatic stereotypes of linguistic homogenisation and monolingualism (Blommaert \& Rampton 2011). Then, I explore how the audience perceives the representation of stylistic choices in mass culture texts and, more specifically, in the analysed advertisement. My informants were 96 students of the last two grades of a Greek elementary school. The recipients' responses show that their metapragmatic stereotypes are aligned with the dominant ones: they approach stylistic choices as strictly-defined systems used in specific social contexts and they expect the alignment of $T V$ fictional characters with linguistic homogeneity. My findings suggest that humour stigmatises specific styles, and that the audience perceive the respective (and reinforced through humour) metapragmatic stereotypes as guidelines for "correct" stylistic use. Furthermore, it seems that through humour, such stereotypes usually go unnoticed in mass culture texts and may even become naturalised, as they are framed in a "trivial" and "non-serious" manner.
\end{abstract}

Keywords: Metapragmatic stereotypes, stylistic humour, style, linguistic homogeneity, mass culture texts. 


\section{Introduction}

Mass culture texts (such as TV texts, songs, advertisements, theatrical plays, films etc.) usually represent a new multi-styled sociolinguistic world: linguistic homogeneity, monolingualism and strict stylistic boundaries have been replaced by a wide variety of languages and speech styles. The use of a standard style is no longer a requirement for the speakers exposed to the media, as the co-existence of different stylistic choices is a frequent phenomenon. However, this combination of different styles usually aims for a humorous effect. More specifically, this juxtaposition of styles is usually represented by the creators of mass culture texts as humorous and incongruous, and this representation is perceived by the audience in a similar way. This kind of humour emerging from the co-existence of different stylistic choices is called stylistic humour (Attardo 1994, 2001, 2009).

Stylistic humour seems to be one of the main and most frequent humorous devices in Greek mass culture texts and seems to be "particularly appreciated by Greek audiences" (Antonopoulou 2004: 238). Through stylistic humour, mass media has the power to impose specific metapragmatic stereotypes (Agha 2007: 148) about how language should or should not be used and thus, it has the potential to shape speakers' views and attitudes about language use. Via framing style mixing as humorous and incongruous, the creators of mass culture texts may marginalise such multistyled practices and (further) stigmatise non-standard styles (Archakis et al. 2014, 2015). On the other hand, stylistic humour in mass culture texts can be identified only if the presupposed metapragmatic stereotypes promoted by the creators of mass culture texts are compatible or even identical with those of the audience. No humour can be perceived or detected if such metapragmatic stereotypes are not shared by the creators of mass culture texts and the audience.

Given the above, in this study I explore both the humourists' and the viewers' metapragmatic stereotypes for the humorous interpretation and perception of mass culture texts. More specifically, I analyse a popular Greek TV advertisement and I intend to bring to the surface the metapragmatic stereotypes that underlie the humorous representation of the protagonists. Then, I aim to explore how the audience perceive this TV advertisement, and to identify the metapragmatic stereotypes underlying their perceptions. It is worth mentioning that previous research concentrates on the mass media creators' metapragmatic stereotypes, and not on the metapragmatic stereotypes guiding the audience's perception of these texts. This study highlights the fact that both the Greek creators of mass culture texts and Greek TV viewers share a variety of metapragmatic stereotypes on the use of different styles and their mixing. Specifically, both parties share a variety of metapragmatic stereotypes on speakers' stylistic choices.

In what follows, I first offer working definitions of the main theoretical concepts employed here: style, humour, stylistic humour, and metapragmatic stereotypes, and I discuss how through stylistic humour, mass media contributes to the strengthening of the dominant metapragmatic stereotypes of language homogeneity and monolingualism (see Section 2). Then, I describe the methodology implemented for designing and conducting the study (see Section 3). In Section 4, I present the analysis of the TV advertisement, where specific metapragmatic stereotypes on stylistic use emerge from stylistic humour. Then, I explore the audience's perceptions of the protagonists' stylistic choices and I identify the metapragmatic stereotypes underlying their perceptions (see Section 5). Finally, Section 6 rounds up the discussion and offers some concluding remarks combining the findings of the textual analysis with the findings of the audience's perceptions. 


\section{Theoretical framework}

\subsection{Style, humour and stylistic humour}

Traditional linguistics placed particular emphasis on strict linguistic boundaries and the connection of languages and language varieties with specific geographical and/or social contexts. In other words, a language variety used by a speaker was considered to reflect the place of origin and the social group to which s/he belonged (Hudson 1996). Current research views languages and language varieties not as bounded, fixed and static language systems, but as different and interconnected styles (Johnstone 2009: 160; Busch 2012: 506; Eckert 2012: 98). Coupland (2007: 103) defines styles as the different ways of speaking involving various phonological, morphological and lexical features. In this light, different kinds of variation (such as geographical, social and functional) are brought together under the broader category of stylistic variation, which refers to the different language choices of speakers (Coupland 2007: 2, 32-37). In this sense, speakers have the opportunity to combine different linguistic features to construct aspects of their social identities and to create their social relationships in a particular context (Coupland 2007: 2-9, 18). Drawing upon a broad linguistic repertoire, style refers to a vast array of social identities in which speakers are involved (Coupland 2007: 146).

Different stylistic choices, and particularly the transition from one variety to another, are accounted for through the concept of crossing (Rampton 1995, 2006). Crossing is the adoption of a stylistic code, form or variety by speakers who are not considered to be accepted members of the social group that primarily uses this code. In other words, speakers may adopt a linguistic behaviour that (stereo)typically belongs to a different social group, in order to show their wish to be identified with that particular group. What is important to note here is that, crossing is a creative process that generates new meanings which are, in turn, associated with the construction of identities in a creative and often unpredictable way. Crossing is therefore included in the study of style in a dynamic way, as meanings are re-defined, re-negotiated, re-interpreted; hence, the one-to-one correspondence between linguistic features and social categories is questioned.

Nevertheless, the creative combination of diverse stylistic resources, which often involves language crossing, is not always considered as expected and natural; on the contrary, it is often taken as deviant and marked, and may even stigmatise the speakers who engage in it. The incongruous use of language varieties that produces humour targeting the speakers who make such stylistic choices has been described as register/stylistic humour (see Attardo 1994, 2001, 2009). Taking into account that humour is based on incongruity, i.e. the opposition between the actual and the expected, the incongruity emerging from the use of diverse, incompatible stylistic resources within a specific context can be seen as stylistic humour. Stylistic humour can be generated by the mixing of different varieties (one of which is unexpected or unconventional) or by replacing the expected variety with an unexpected one (Attardo 2009: 315). As Kubovy (1999) states, the violation of language expectations and the undermining of the unexpected variation play a decisive role in achieving a humorous effect. The violation of expectations clearly echoes the concept of humorous incongruity, while undermining harks back to the superiority theory that approaches humour as the expression of a sense of superiority towards people or situations that we consider as inferior (see Raskin 1985: 36-37). The violation of linguistic expectations and the undermining of the unexpected variation are perceived by the speakers as stylistic humour only if they are aware of the social conditions and the cognitive specification of this particular speech community (cf. Apter 1982, Wyer \& Collins 1992; see also Canestrari et al. 2018).

Given the above, I intend to argue that stylistic humour functions as a means of deterring speakers from using stylistic resources in an incongruous manner. In other words, this kind of humour constitutes an effective way of convincing or even forcing speakers to conform to 
specific rules of "appropriate" and "correct" stylistic behaviour. It could, therefore, be suggested that the stylistic humour becomes a rhetoric device and "a means of disciplinary teaching" (Billig 2005: 177) as to how styles are expected to be used in specific contexts. This capacity of stylistic humour to transmit and to impose specific metapragmatic stereotypes on speakers is examined in the present study.

\subsection{Humour, stylistic humour and metapragmatic stereotypes}

Humour is not inherent in things, as reality never speaks for itself. Individuals perceive reality in a specific (humorous, serious, etc.) way depending on the interpretative viewpoint they decide to adopt (Pickering \& Lockyer 2005: 15). As El Refaie (2011: 87) points out, "a joke can be humorous to one person, and utterly unfunny or even offensive to a different person or indeed to the same person under different circumstances". In other words, humour constitutes the conscious choice of each speaker who perceives an event as unusual and unexpected, and then responds to it in a humorous manner. From this perspective, humour can be perceived as a means of assessing things and it can be linked with evaluation, namely the attitudes and the feelings of the producer of a text vis-à-vis what s/he says or writes. Based on a divergence from the norm, humour is directly connected with the critical attitude towards divergence. As a consequence, humour brings to light the values, the ideologies, beliefs and stereotypes in relation to which incongruity is found within a specific social and cultural context (Tsakona 2013: 35-36). In a similar vein, stylistic humour brings to light the ideological models for language use, particularly about styles or language varieties. Stylistic humour is based on a priori assumptions about the contextual variables of style, which predict the use of certain linguistic realisations (Simpson 2003: 75). In this sense, stylistic humour reflects, sustains, and reproduces specific metapragmatic stereotypes about styles or language varieties.

Metapragmatic stereotypes constitute speakers' internalised models of how language should or should not be used; such "culture-internal models of utterance" guide speakers' own language use and enable them to make evaluations about their own language behaviour or that of others (Agha 2004: 25, 2007: 148; see also Agha 1998). These stereotypes originate in language use and evaluation, are socially circulated, and affect the interactions between the speakers of a linguistic community. Based on metapragmatic stereotypes, individuals express their attitudes on how specific linguistic features function in social interaction. Speakers either express their views on various language elements directly, namely through describing them as "right", "wrong", "appropriate", "inappropriate", "common", "unusual" and so on, or express their evaluative judgments indirectly, namely through associating specific language elements with different social characteristics (e.g. woman, upper-class person), communicative situations (formality, politeness) and/or social practices (e.g. religious, literary or scientific activity) (cf. Xydopoulos et al. in press). Hence, via investigating which stylistic performances are framed and perceived as incongruous, we could trace what seem to be speakers' metapragmatic stereotypes concerning the "correct" use of stylistic choices. The mere fact that some stylistic uses are considered incongruous points to the implicit presence of specific metapragmatic stereotypes on how styles are or should be employed. I will, therefore, show that stylistic humour brings to the surface specific metapragmatic stereotypes on style which are presupposed and reinforced both by the creators of mass culture texts and by the audience.

\subsection{Metapragmatic stereotypes and stylistic humour: The production and perception of mass culture texts}

It is by now a truism to say that mass culture texts contribute to the (in)direct enforcement of dominant ideological beliefs and values and to shaping and constructing speakers' identities. In particular, mass culture texts frame collective memory and common experiences, thus bringing 
together viewers from different backgrounds (Van den Bulck 2001: 55). Such texts merge "the marginal with the dominant, the parochial with the cosmopolitan and the local with the global," and have the ability to form the stances of the audience in relation to these concepts (Johnson \& Ensslin 2007: 14). Regarding the ideological beliefs about language, mass media more often than not endorse dominant metapragmatic stereotypes promoting the imposition of a single, homogeneous and idealised style (Van den Bulck 2001; Stuart-Smith 2006; Moody 2013). The promotion of these stereotypes is most significant in western nation states, where the need for one common language gave rise to dominant metapragmatic stereotypes of monolingualism and language homogeneity and excluded language varieties which were often stigmatised (Blommaert \& Rampton 2011: 3-4).

Linguistic homogeneity and monolingualism are based on the idea that languages and language varieties are strictly bounded systems, used in specific, also bounded, social formations (Blommaert \& Rampton 2011; Busch 2012; Heller 2007; Jørgensen \& Juffermans 2011; Liakos 2005: 53). Linguistic homogeneity and monolingualism imply some sort of categorisation and grouping (of, e.g., users, social features, languages, linguistic varieties and associated practices) which are mostly based on the assumption of a pre-existing similarity, but it can also be the result of socio-cultural invention and/or imposition (Busch 2012: 506). In this sense, a speech variety is defined by the socio-cultural group to which its users belong, and/or the social setting where it is used, hence, it can be more or less predictable. Therefore, the metapragmatic stereotypes of language homogeneity and monolingualism imply a consensus that languages and linguistic varieties are seen as autonomous structures used in established socio-cultural frames (Heller 2007: 11; Blommaert \& Rampton 2011: 4; Busch 2012: 506-507).

Recent sociolinguistic research suggests that Greek mass culture texts tend to confirm and reproduce the dominant metapragmatic stereotypes of linguistic homogeneity and monolingualism through stylistic humour (Georgakopoulou 2000; Stamou 2012a). Such humour is used for characterisation, that is, for ascribing specific attributes to the characters of such texts, which more often than not contributes to their humorous dimension. More specifically, characters opt for a formal or high style where an informal or low one is expected, or vice versa; or they "inappropriately" mix different styles in their effort to address different audiences; in general, they draw on a style which does not fit the occasion. In most of such cases, the characters are portrayed as communicatively incompetent and hence, embarrass themselves by becoming the targets of humour. Thus, stylistic humour usually promotes and reinforces the imposition/prevalence of a single and idealised linguistic norm: it serves as guidelines for "appropriate" language use and promotes the existence of (and thus the preference for) a "default" and "omnipresent" style, which could potentially be used by all speakers in all contexts. In this sense, this kind of humour reflects, sustains and reproduces the dominant metapragmatic stereotypes of linguistic homogeneity and monolingualism (Bainschab-Damaris 2009; Berglin 2009; Gardner 2010; Tsami et al. 2014).

Stylistic humour has attracted the attention of Greek sociolinguists who investigate the phenomenon in mass culture texts, such as newspaper humour columns (Canakis 1994), internet memes (Piata 2019), film comedies (Georgakopoulou 2000), humorous short stories (Tsakona 2004), TV comedies (Stamou 2011) and children's books (Stamou 2012b). However, all these studies concentrate on creators' metapragmatic stereotypes, and not on the metapragmatic stereotypes guiding the audience's perception of these texts. Stylistic humour in mass culture texts can be identified only if the presupposed metapragmatic stereotypes promoted by the creators of mass culture texts are compatible or even identical with those of the audience (see also Irvine 2001: 25). Therefore, viewers can perceive as incongruous, deviant and laughable any style mixing or any style other than the standard language, only if they carry and reproduce the metapragmatic stereotypes of linguistic homogeneity and monolingualism. In this sense, stylistic humour can bring to the surface the people's common ground, and remind us that 
humourist(s) and viewer(s) must have a set of common metapragmatic stereotypes, assumptions and values in order to share a joke (cf. Archakis \& Tsakona 2005, 2006, 2011: 99-100). If such metapragmatic stereotypes are not shared both by the humourists and the audience, humour may fail.

Given the above, in this study, I intend, on the one hand, to concentrate on the metapragmatic stereotypes that humourists employ in Greek mass culture texts and, on the other, to explore how the audience perceive this text and to identify the metapragmatic stereotypes underlying their humorous perceptions.

\section{Methodology}

My dataset consists of 29 extracts which come from a wide range of genres, including popular TV series (mostly sitcoms), advertisements, song lyrics and films. All of them were broadcast within the years 2001-2012 (see also Tsami 2018). The example examined here is a popular advertisement of a telecommunications company, which was frequently broadcast on Greek TV during the years 2011-2012. Firstly, I conduct a qualitative analysis of this advertisement and concentrate on the metapragmatic stereotypes that the creator of the text evoked to produce stylistic humour (see Section 4). Secondly, I explore how the audience perceive this text and I intend to identify the metapragmatic stereotypes underlying their humorous perceptions.

The present study (both the analysis and the perception test) was conducted in the context of the research project "Thalis (2011-2015): Linguistic variation and language ideologies in mass cultural texts: Design, development and assessment of learning material for critical language awareness". The present project explores the possibility of utilising mass culture texts in pre-school, primary school and high school language teaching. More specifically, the aim of the project is the design, development and assessment of learning material in order to raise students' critical awareness of language varieties. For the implementation of this project, three research teams cooperated (a research team in the University of Western Macedonia, one in the University of Patras, and one in the Aristotle University of Thessaloniki). Each of them focused on students at a different level (pre-school, primary school and high school students respectively).

In this context, the perception study was conducted in four public elementary schools, since my research team (University of Patras) concentrated on primary school students. More specifically, these schools were located in the wider region of Achaia, a prefecture of Western Greece. The research focuses on 96 elementary school students in the $5^{\text {th }}$ and $6^{\text {th }}$ grade: 53 boys and 43 girls, with an average age of 11.6 years $(S D=0.56)$. It is acknowledged that at this age, typically developing children can conceive riddles and jokes based on incongruity and resolution (Bergen 2018; McGhee 2018), so the question raised here is if and how these students perceive stylistic humour.

The students were asked to watch the TV advertisement, which functioned as a stimulus, and then to complete an anonymous closed-ended responses questionnaire. The questions examined if the students considered speakers' stylistic choices as incongruous and humorous and focused on the metapragmatic stereotypes underlying their humorous perceptions. More specifically, the questions investigated students' metapragmatic stereotypes about the geographical (urban, semi-urban or rural) and communicative (formal or informal) contexts of dialectal use. The questions also explored students' dominant metapragmatic stereotypes about style mixing. Students' answers to the questions were classified on a four-point scale $(1=$ Not at all likely, $2=$ A little likely, $3=$ Quite likely, $4=$ Very likely). The three sets of questions described above aimed to identify the geographical context and circumstances (communicative and professional) in which students consider the use of geographical varieties acceptable. 
Another set of 17 questions was included in the students' questionnaire, asking our informants to evaluate directly the geographical variety that was used by the TV commercial characters, with characteristics referring to competence, prestige, reliability, integrity and attractiveness (such as weird, funny, incorrect, beautiful, stupid, unappealing, outdated, cheerful, useless, indifferent, incongruous, friendly, important, intelligent, rustic and insignificant). These questions were aimed to elicit students' opinions on the overt and covert prestige ${ }^{1}$ of geographical varieties and dialectal speakers. The data collection process lasted approximately a month (May 2013). After a pilot implementation, the questionnaires were administered to the participating schools and completed by the students of the sample in their teacher's presence and mine (as a researcher).

For the analysis of the data collected with the questionnaire, we employed the nonparametric statistical test-One-Sample Chi-Square Test-as the dependent variables were nominal and ordinal.

\section{Analysing stylistic humour in mass culture texts}

In what follows, I analyse the humorous Greek advertisement of the telecommunications company used for research purposes (I bar my heart Kitsos and Tasoula Vodafone new 2012). The plot is set in a hypothetical regional place, presumably a village, and represents the romance between two speakers of a regional Greek variety. In the following analysis, I intend to bring to the surface the metapragmatic stereotypes exploited for the humorous representation of the protagonists. $^{2}$

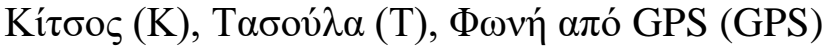

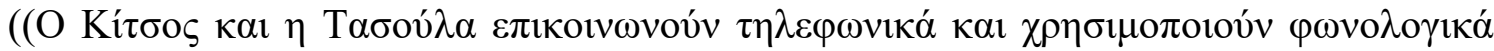

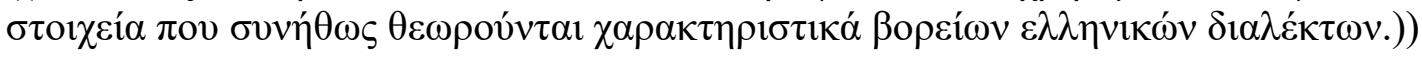

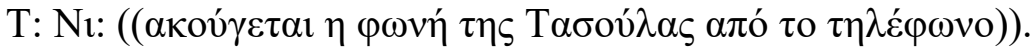

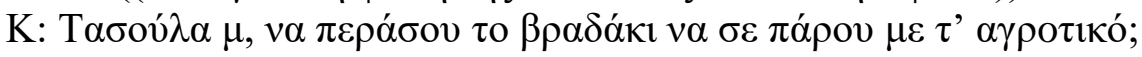

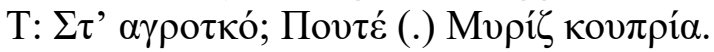

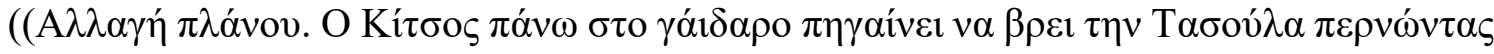

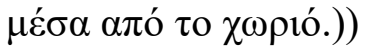

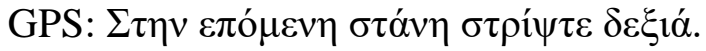

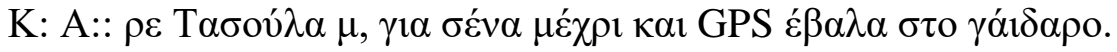

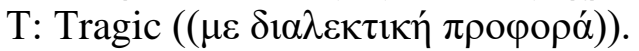

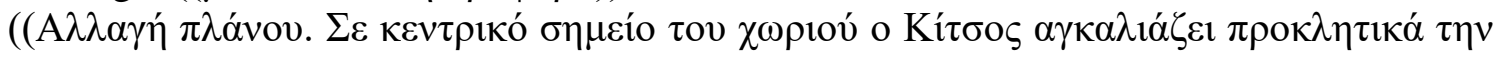

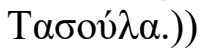

\footnotetext{
${ }^{1}$ Prestige is the social value which is ascribed to a specific language or dialect within a speech community, relative to other languages or dialects. A prestigious variety (e.g. the standard variety) has overt prestige, as it is socially and widely acknowledged as "correct" and is, therefore, valued highly among all speakers of the speech community. Non-standard varieties are often said to have covert prestige ascribed to them by their speakers. More specifically, a covert prestige variety is usually not accepted in all social groups (e.g. youth language), but a specific, small group of speakers shows positive evaluation of and orientation towards this linguistic variety (Eckert \& Rickford 2002).

2 The extract is presented in Greek followed by its translation in English. Slang terms and expressions have been translated to pragmatically equivalent English ones. The following transcription symbols are used; $((\mathrm{xxx}))$ : Clarification points made by author; xxx : Stressed parts of utterance; xxx:: : Elongation of a previous sound; . : Falling intonational shift; , : Non final intonation; ; : Rising intonational shift (in the Greek original); ? : Rising intonational shift (in the English translation); (.) : Pause of less than two tenths of a second.
} 


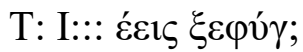

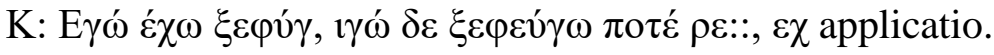

$\mathrm{T}: \mathrm{Tl} \varepsilon \dot{\varepsilon} \varepsilon \dot{\varepsilon} ;$

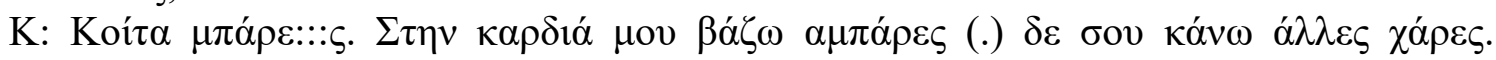

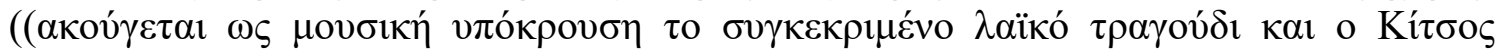

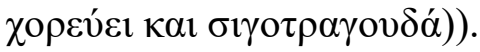

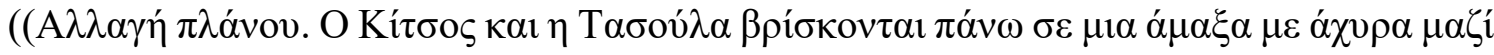

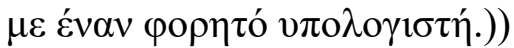

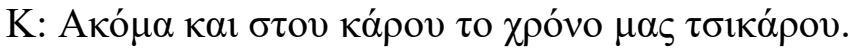

$\mathrm{T}: \mathrm{Kí} \tau \sigma o v::$

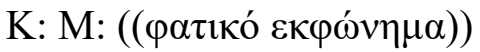

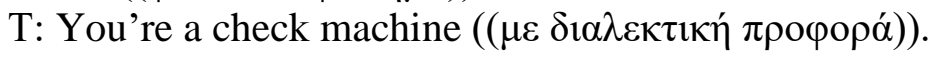

Kitsos (K), Tasoula (T), GPS voice (GPS)

((Kitsos and Tasoula speak on the phone and they employ phonological features stereotypically associated with northern, low-prestige Greek dialects.))

T: Yu:p ((a female voice, obviously Tasoula's, is heard))

$\mathrm{K}$ : Tasoula $\mathrm{m}^{3}$ can I stop by this evening to pick you up with the pick-up truck?

T: In the pick-up truck? Never (.) It smells of manure.

((Change of scene. Kitsos on a donkey crosses the village to meet Tasoula.))

GPS: In the next sheepfold turn right.

K: O::h my Tasoula, I even put a GPS on the donkey for you.

T: Tragic ((in English but uttered in a local accent)).

((Change of scene. Kitsos provocatively hugs Tasoula in a central location of the village.))

T: I::: ${ }^{4}$ have you lost it?

K: Have I lost it, I never lose it re::.:., I've application.

T: What?

K: See ba:::rs. I bar ((lock)) my heart (.) don't ask for more ((lyrics from a folk song that is heard as being played on the mobile while Kitsos is dancing and singing it)).

((Change of scene. Kitsos and Tasoula are on a carriage loaded with hay on which a laptop is placed.))

$\mathrm{K}$ : Even on the carriage I check our time left.

T: Kitsos::

$\mathrm{K}: \mathrm{M}:(($ phatic utterance $))$

T: You're a check machine ((in English but uttered in a local accent)).

Kitsos's and Tasoula's stylistic choices include features from a Greek provincial geographical variety. This is, however, not a distinct, documented language variety. Rather, it draws on features from several northern Greek dialects and constitutes a stereotypical way of stylising the average speaker from rural Greece. Northern Greek varieties present a shift from $/ \mathrm{o} /$ to $/ \mathrm{u} /$ which is extensively observed in the speech of Kitsos and Tasoula (e.g. $\pi \alpha \dot{\rho} \rho o v$ [páru] instead of the standard $\pi \dot{\alpha} \rho \omega$ [páro] "I pick up", $\pi$ ov $\tau \dot{\varepsilon}$ [puté] instead of $\pi o \tau \varepsilon \dot{\varepsilon}$ [poté] "never",

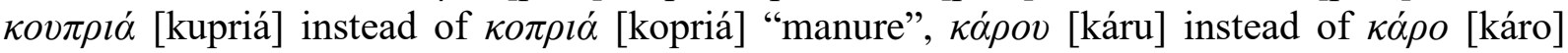
"cart"). Another feature of northern dialects is the drop of the stressless vowel [i] (e.g. $\alpha \gamma \rho o \tau \kappa o ́$

\footnotetext{
${ }^{3} \mu[\mathrm{m}]$ "my/ mine" is the northern dialectal variant corresponding to the standard $\mu$ ov [mu].

${ }^{4}$ Interjection, typical of northern Greek dialect.

${ }^{5} R e$ is an untranslatable marker that signals, among others, intimacy.
} 


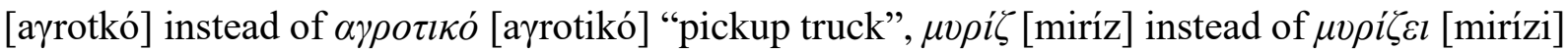
"it smells", $\xi \varepsilon \varphi v ́ \gamma$ [ksefíj] instead of $\xi \varepsilon \varphi v ́ \gamma \varepsilon \iota[$ [ksefíji] "lost").

However, Kitsos appears to be a farmer familiar with the new technology (mobile phone, laptop, GPS) and uses the language variety of computing and mobile technology in his attempt

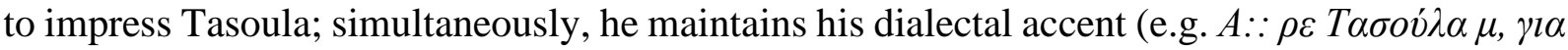

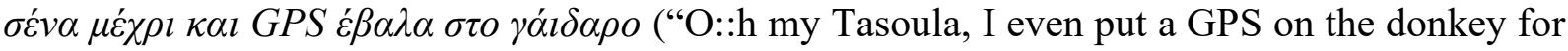

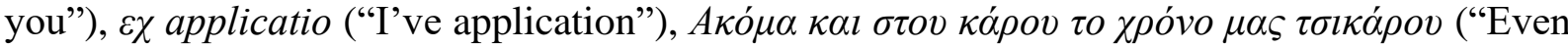
on the carriage I check our time left"). Tasoula, in turn, uses English phrases to show her disapproval of the village mentality and its related practices and, consequently, to come across as a modern woman; once again, her English phrases co-exist with her dialectal accent (e.g. tragic, you're a check machine).

It could be suggested that the dialect is used in its "natural place", that is, in everyday contexts among peers/intimates (telephone communication, in the village square, on the cart). However, the advertised products (mobile telephone applications) are represented as completely incompatible with the physical space in which the plot is set. Throughout the advertisement, the merging of geographical style with the styles of computing and mobile technology constitutes a central vehicle of stylistic humour and is represented as incongruous (see also Archakis et al. 2014; Tsami et al. 2014).

Through this humorous representation, Kitsos and Tasoula's "incongruous" styles reveal a chain of interrelated metapragmatic stereotypes on stylistic use:

- it is implied that language varieties are strictly bounded systems, used in specific, restricted, social and geographical contexts, so as not to appear "strange", "odd", "deviant", "incongruous" and/or "humorous";

- it is also implied that the use of a geographical variety is expected in rural areas and informal communicative settings;

- the variety of computing and mobile technology is expected to be used by individuals of higher social status in formal and urban communicative settings;

- the mixing of "high prestige" stylistic choices (e.g. English, the variety of computing and mobile technology) with dialectal stylistic elements is framed as "strange" and "deviant";

- $\quad$ speakers that attempt "unsuccessful" language crossings are linguistically and socially incompetent, restricted to particular settings and contexts and hence, incongruous and laughable.

To sum up, normalised metapragmatic stereotypes are reproduced in this humorous ad: how one should speak and behave and what kind of lifestyle (s)he should adopt, as the profiling of the protagonists dictates a specific, expected linguistic and stylistic behaviour. More specifically, stylistic humour helps to establish clear-cut boundaries between the geographical style and the styles of computing and mobile technology and to present geographical style as restricted to its "natural" place. The protagonists of the advertisement become the targets of humour because of their attempt to cross from the geographical style to forms that do not stereotypically belong to them. So, the co-existence of various, contrasting styles is negatively evaluated and humorously stigmatised, while linguistic homogeneity and the preference for a "single", "neutral" style come into play. 


\section{The perception of stylistic humour in mass culture texts}

In what follows, I aim to explore how the audience perceive this TV advertisement and to identify the metapragmatic stereotypes underlying their perceptions. As already mentioned (see Section 3), 96 elementary school students were asked to watch the TV advertisement and then to complete an anonymous questionnaire, including closed questions. First of all, through these questions, I examine if the students consider Kitsos and Tasoula's stylistic choices as incongruous and humorous. Then, I attempt to find out which metapragmatic stereotypes underlie students' humorous perceptions. More specifically, I investigate students' metapragmatic stereotypes about the geographical and communicative contexts of dialectal use. I also explore students' dominant metapragmatic stereotypes about style mixing. All such metapragmatic stereotypes play a decisive role in students' perceptions of the dialect as incongruous in specific contexts. Based on such stereotypes, students evaluated and characterised the stylistic choices of the TV characters as "correct", "appropriate" and "expected" or as "incorrect", "incongruous" and "humorous".

So, first, students were asked about the degree of incongruity and the degree of funniness of Kitsos and Tasoula's stylistic choices.

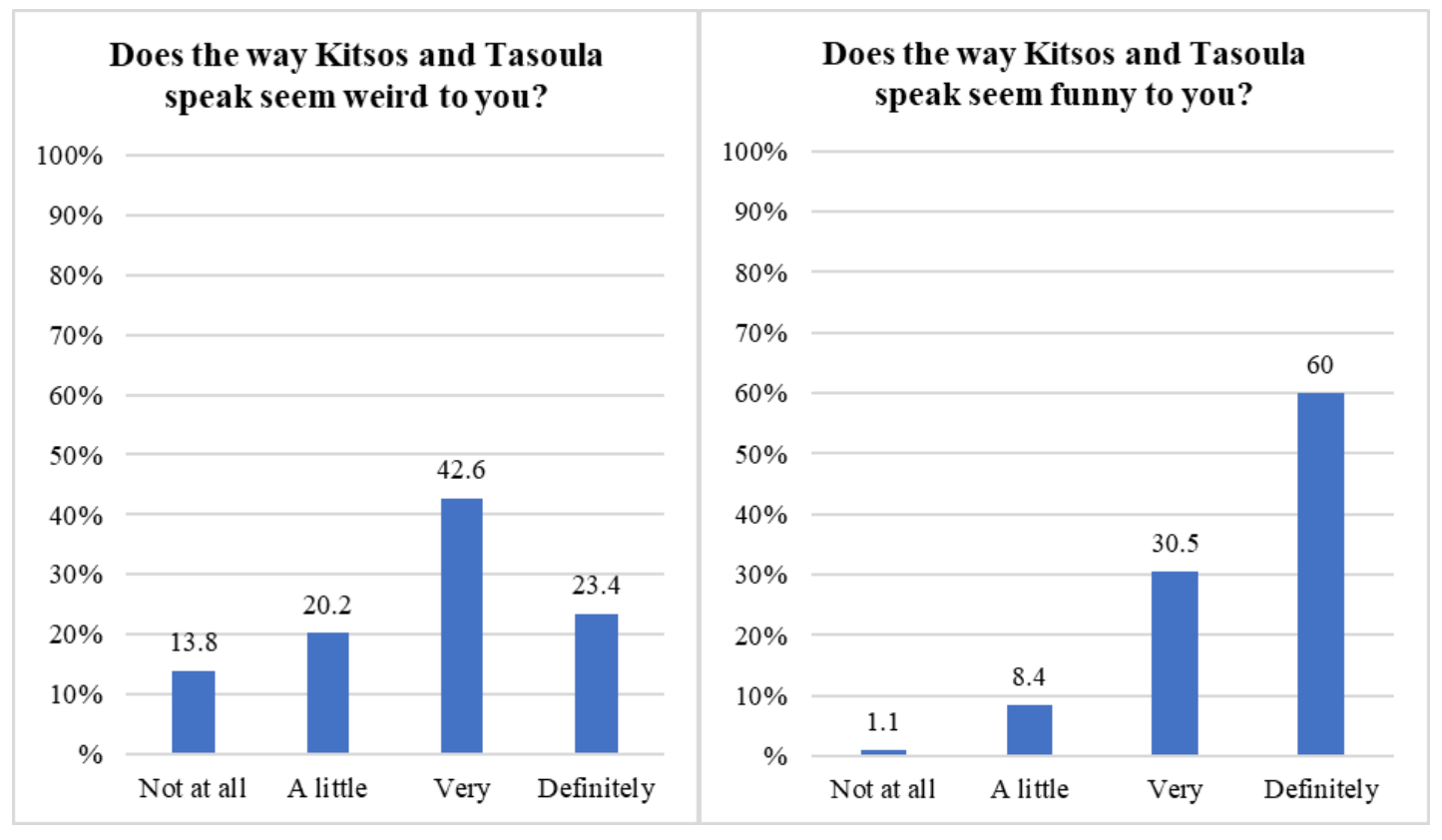

Figure 1

Figure 2

Figures 1 and 2: Histograms showing students' views about the incongruity and funniness of the protagonists' stylistic choices

Figures 1 and 2 show that most students of our sample consider Kitsos and Tasoula's way of speaking as "weird" and "funny". Specifically, Figure 1 shows that 42.6 per cent of the students consider Kitsos and Tasoula's way of speaking to be "very" weird, while 23.4 per cent of the students replied that the protagonists' stylistic choices were "definitely" weird. It seems that the positive responses "Very" and "Definitely" together amounted to 66 per cent. Students had a similar attitude towards the degree of funniness of Kitsos and Tasoula's way of speaking. Figure 2 shows that 60 per cent of the students consider Kitsos and Tasoula's way of speaking to be "definitely" funny, while 30.5 per cent of the students replied that the protagonists' stylistic choices were "very" funny. It seems that the positive responses "Very" and "Definitely" together amounted to 90.5 per cent. The percentages of Figures 1 and 2 indicate that students perceive 
the stylistic choices of Kitsos and Tasoula as incongruous and they choose humour as the main reaction to this incongruity. The One-Sample Chi-Square Test showed the above findings to be statistically significant (Figure 1: $X^{2}(3, N=94)=17.234, p<0.05$, Figure 2: $X^{2}(3, N=95)=$ 79.947, $p<0.05)$.

Then, I explore which metapragmatic stereotypes underlie students' incongruous and humorous perceptions. So, I investigate students' metapragmatic stereotypes about the geographical and communicative contexts where the use of the dialect is expected to appear.

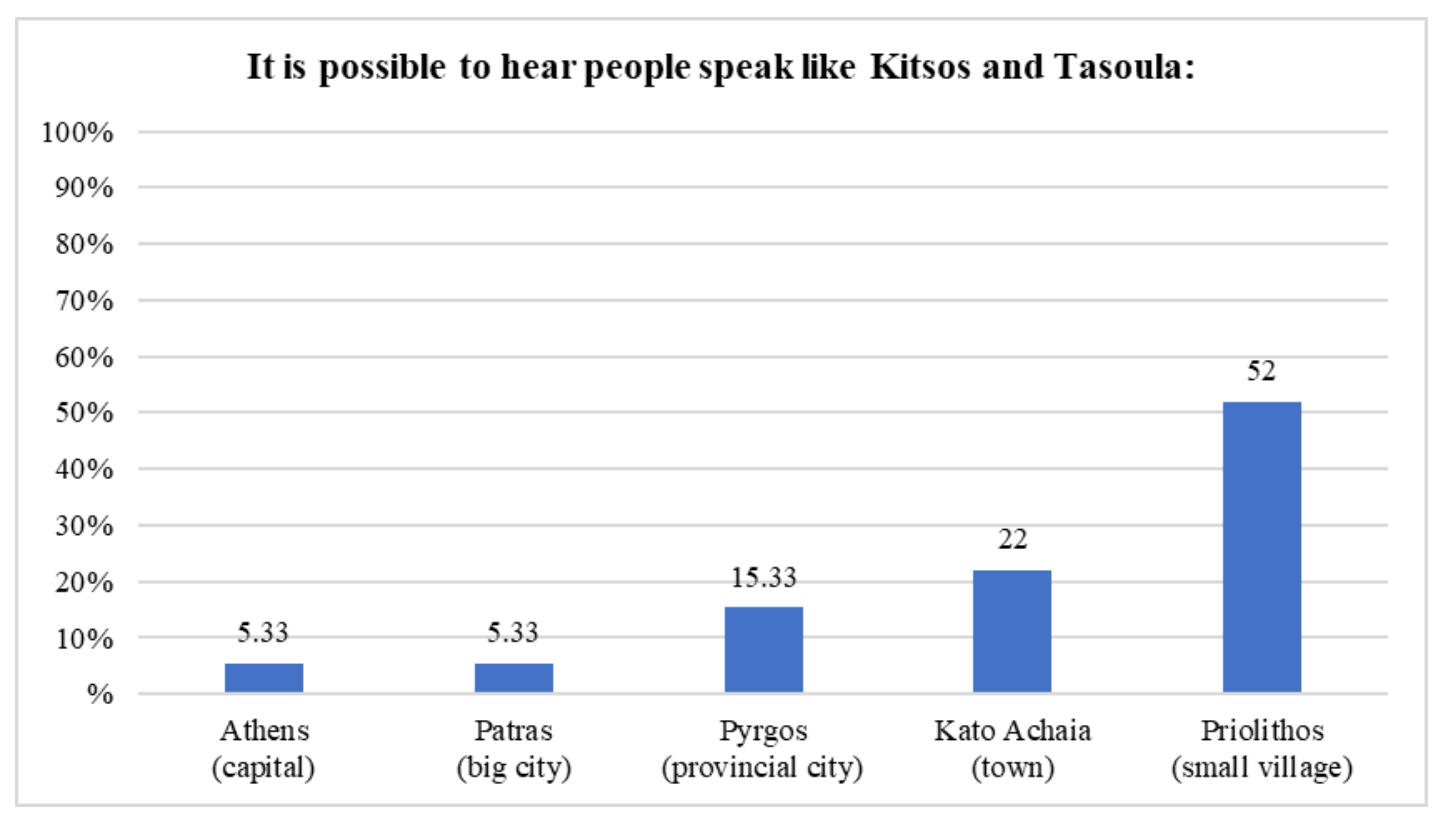

Figure 3: Histogram of the geographical areas where the use of a dialect is expected to appear

Figure 3 shows that most students in our sample expect the regional variety under study to be used more frequently in rural areas. Specifically, it seems that students do not expect the use of the dialect in large cities, such as Athens or Patras, as only a small percentage chose these areas as locations where they expect to hear a dialect. This percentage is higher for provincial cities, such as Pyrgos, and towns, such as Kato Achaia. Lastly, a significantly high percentage of the students of our sample expect the use of a geographical variety in a small village. The percentages in Figure 3 indicate a dominant metapragmatic stereotype from students: the use of the dialect is expected in rural environments and in small villages. Students consider that the dialect in the advertisement is used in its "natural place", so this stereotype does not challenge their humorous reaction. The One-Sample Chi-Square Test showed the above findings to be statistically significant (Figure 3: $\left.X^{2}(4, N=150)=111, p<0.05\right)$. 


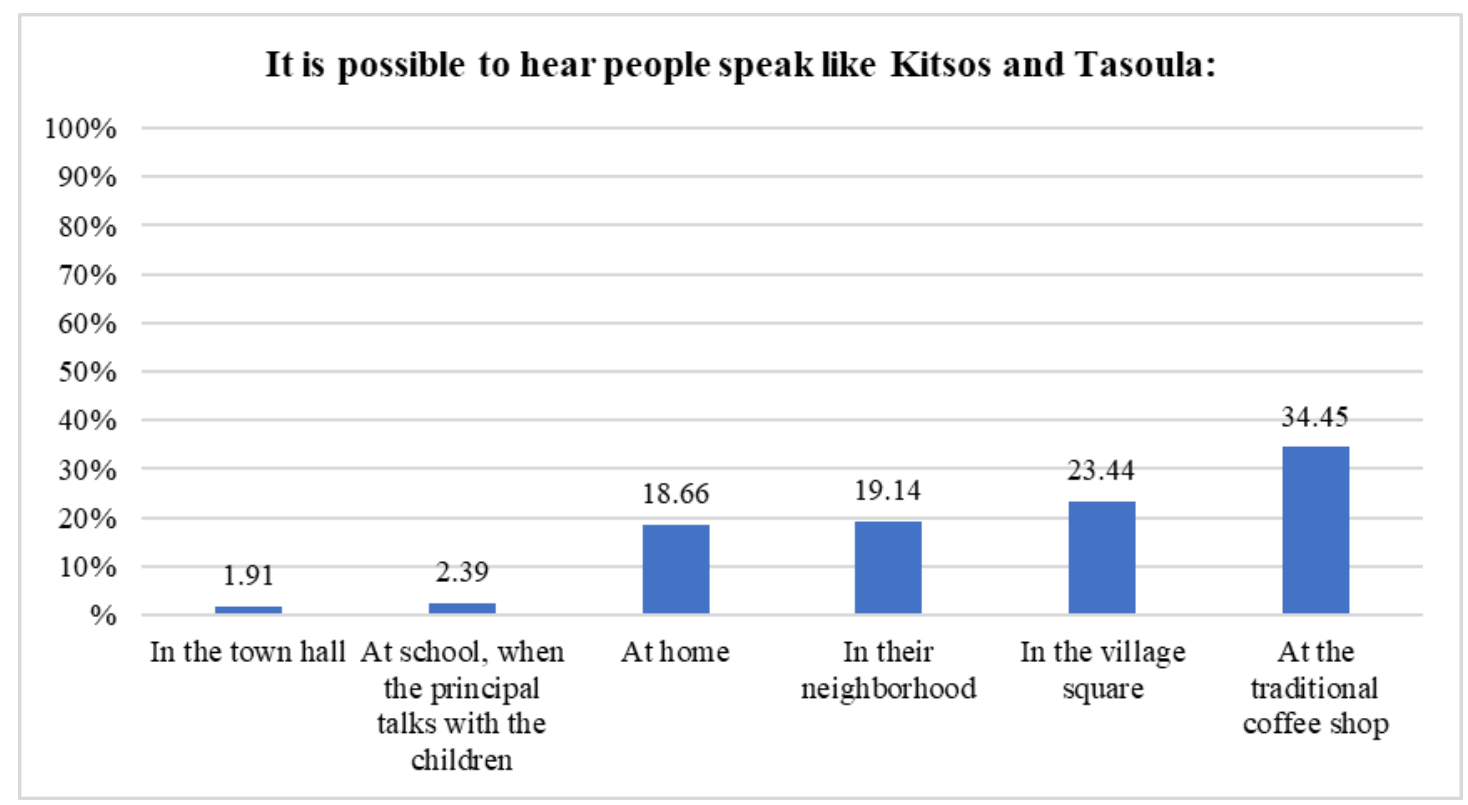

Figure 4: Histogram showing the communicative settings of dialectal use

With regard to the communicative settings appropriate for the use of a dialect, Figure 4 shows that students do not expect the use of a dialect in the town hall or at school (percentage of 1.91 per cent and 2.39 per cent, respectively). In other words, students consider the town hall and the school to be formal communicative settings, where dialectal use is perceived to be out of place. On the other hand, they consider it more likely to encounter dialectal speech in more informal communicative settings, such as at home (18.66 per cent), in their neighbourhood (19.14 per cent) and in the village square (23.44 per cent). Students view the traditional coffee shop as the most likely communicative environment for the use of a geographical variety (34.45 per cent). The latter finding is not surprising, as traditional coffee shops in Greece are the places where elderly men socialise daily with their peers. Therefore, students' responses indicate that their views are dominated by the following metapragmatic stereotype: the dialect should be used in everyday and informal contexts. Under the influence of this stereotype, students perceive the use of the dialect as "expected" in informal settings. The One-Sample Chi-Square Test showed the above findings to be statistically significant (Figure $\left.4: X^{2}(4, N=209)=99.526, p<0.05\right){ }^{6}$

In order to delve into the use of dialect in formal communicative settings, we asked the students if they would expect to hear dialectal speech, similar to the speech of the TV characters in the commercial, from a teacher in the classroom, a journalist on television, or a doctor at his/her office. Figures 5, 6 and 7 show students' overwhelmingly negative response regarding all three formal communicative settings. To all three questions, more than 65 per cent of the students replied "Not at all" (66.3 per cent, 67.7 per cent and 76.6 per cent respectively), while the negative responses "Not at all" and "A little" together amounted for more than 89 per cent (reaching 89.2 per cent for the teacher, 95.8 per cent for the journalist and 96.8 per cent for the doctor). According to students' responses, the doctor's office is the least likely place for a mixing of "high prestige" stylistic choices (e.g. English, the varieties of computing and mobile technology) with dialectal stylistic elements. In fact, the students in our sample do not seem to expect an authority figure, i.e. the doctor, to attempt "unsuccessful" language mixing while working. The journalist comes next and the teacher comes last. This sequence may possibly relate to the fact that children have a more familiar and direct relationship with the teacher, and

\footnotetext{
${ }^{6}$ In Figures 3 and 4, the number of the answers (see $\mathrm{N}=150$ and $\mathrm{N}=209$, respectively) is greater than the number of the sample (see $\mathrm{N}=96$ ), because in these questions, the students could select more than one answer.
} 
therefore, consider it more likely to hear the teacher attempt stylistic mixing in formal communicative settings. On the contrary, the doctor seems to be perceived as a more distant figure, perhaps because of children's fear of doctors. So, in this case, they consider it less likely to hear mixed stylistic choices in a doctor's office. So, students' responses indicate that their views are dominated by the following metapragmatic stereotype: speakers who practise "prestigious" professions and/or communicate in formal circumstances are not expected to perform "unsuccessful" language crossings. The One-Sample Chi-Square Test showed the above results to be statistically significant, with a significance of 0.000 for all three questions (Figure 5: $X^{2}(3, N=96)=110.83, p<0.05$, Figure 6: $X^{2}(4, N=96)=124.21, p<0.05$, Figure $\left.7: X^{2}(3, N=96)=135.58, p<0.05\right)$.

Students were also asked about the two protagonists' proficiency in English. Through these questions, I attempt to detect students' dominant metapragmatic stereotypes about language mixing.

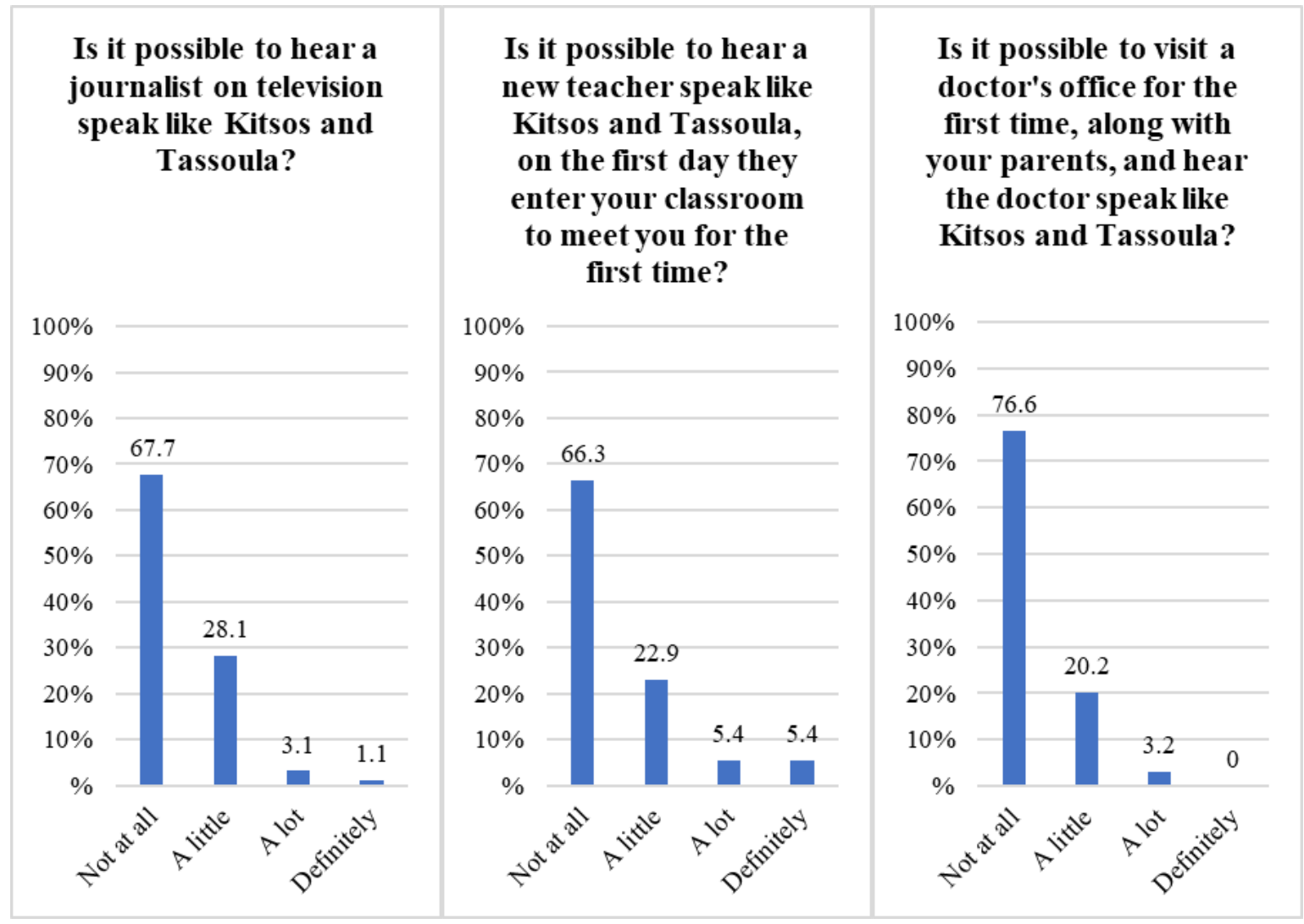

Figures 5, 6 and 7: Histograms showing the connection of formal communicative settings and the "prestigious" professions with language mixing

Figures 8 and 9 show that 29.35 per cent of the students replied "Not at all" about Kitsos' skill with English, while 61.96 per cent of the students replied that he knows English "A little". It seems that the negative responses "Not at all" and "A little" together amounted to 91.31 per cent. Students had similar views about Tasoula's skill with English. Although Kitsos and Tasoula use English words and expressions, students do not consider that they speak English adequately, probably because they maintain their dialectal accent. In other words, these recipients' views are dominated by a specific metapragmatic stereotype about language mixing: high prestige stylistic choices, such as the English language (including English loan words belonging to technological styles), should not be combined with dialectal stylistic choices. So, based on this metapragmatic stereotype, students perceive the language mixing as "strange", 
"unsuccessful", "deviant" and therefore "humorous". The One-Sample Chi-Square Test showed the above findings to be statistically significant (Figure 8: $X^{2}(3, N=96)=85.75, p<0.05$, Figure 9: $\left.X^{2}(4, N=96)=110.56, p<0.05\right)$.

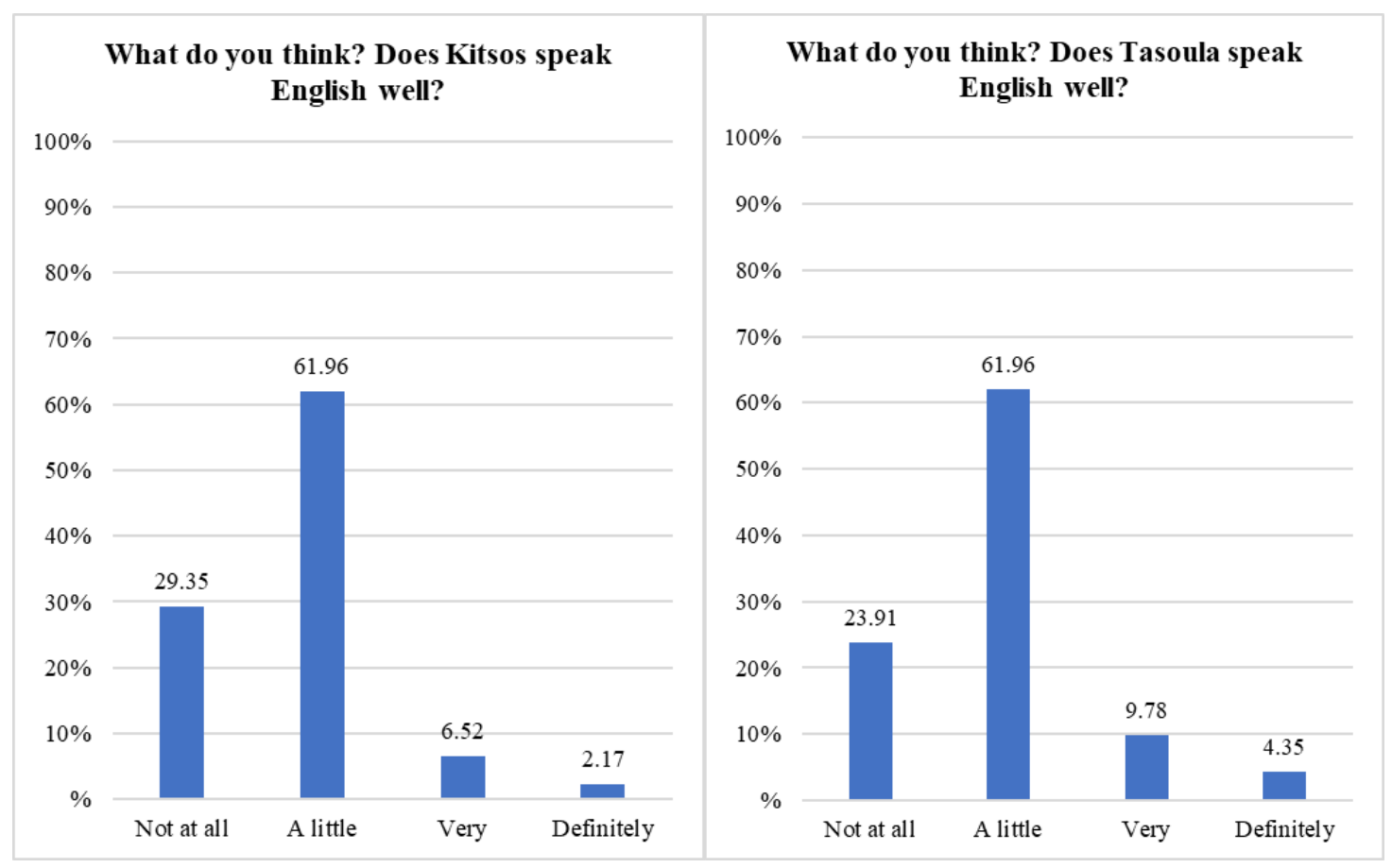

Figures 8 and 9: Histograms showing students' views about the two protagonists' proficiency in English

The results of the above Figures account for the reasons why students perceive the TV advertisement as humorous and laughable. Students' perceptions are strongly affected by a chain of metapragmatic stereotypes on the use of dialects:

- students perceive language varieties as strictly bounded systems, used in specific, restricted social and geographical circumstances, as they expect the use of a geographical variety in rural and informal circumstances;

- students probably consider the mixing of dialectal stylistic elements with "high prestige" stylistic choices (e.g. English, variety of computing and mobile technology) as "strange" and "deviant";

- students do not associate "prestigious" professions and formal communicative settings with speakers who attempt "unsuccessful" language crossings;

- mixing of "high prestige" stylistic choices with dialectal stylistic elements is perceived by the students as a "deviation" and as indicating inadequate knowledge of a "high prestige" style.

Recipients' responses show that their metapragmatic stereotypes are aligned with the dominant ones and that they approach stylistic varieties as homogeneous and strictly-defined systems used in specific geographical and communicative contexts. If specific styles are not restricted in the "appropriate" geographical and communicative settings, students perceive them as "strange", "incongruous" and eventually "humorous". Respectively, speakers that attempt "unsuccessful" language mixing are perceived by students as linguistically and socially incompetent and hence, incongruous and laughable. 


\section{Conclusions: Combining interpretation with perception}

To sum up, the present study investigated the presupposed and dominant metapragmatic stereotypes for the creation and perception of humorous mass culture texts. Such humour presupposes the existence of strict boundaries between styles and strong connections between styles and contexts. So, the humorous framing and perception of such practices does not only presuppose but also recycles and reinforces specific values and attitudes, namely metapragmatic stereotypes, on style use (cf. Hiramoto 2011: 346). If such presuppositions are not shared by the humourist(s) and their audience(s), style mixing and language crossing are perceived as "expected" and not as "incongruous" behaviours; hence no humour can be identified.

Our analysis of the TV ad has demonstrated that such metapragmatic stereotypes are encoded via stylistic humour, which attempts to promote and enhance negative attitudes towards non-standard styles, style mixing and language crossings. This kind of humour works at the expense of non-standard styles, style mixing and language crossing. Therefore, stylistic humour promotes a preference for a "single", "homogeneous" and practically non-existent variety. This idealised, "neutral" construct would be accepted by speakers as the "default" code, would be considered suitable for each and every context, and would cover all kinds of communicative needs. Any deviation from such a variety is represented in mass culture texts as "inappropriate" and becomes the source and the object of humour and laughter.

The quantitative analysis of the questionnaires reveals that students are aware not only of humour in general (see Bergen 2018, McGhee 2018) but also of this specific kind of stylistic humour. This finding indeed confirms that both the producers of humour and the audience align with dominant metapragmatic stereotypes which promote language varieties as strictly bounded systems. Also, they do not seem to question the dominant view of language varieties as distinct and autonomous systems. In other words, the metapragmatic stereotypes of linguistic homogeneity are connected with specific (socio)linguistic expectations. The undermining and violation of these language expectations contribute to experiencing a stimulus as humorous (see Apter 1982, Kubovy 1999, Canestrati et al. 2018). Both the humourists and the audience expect language varieties to function as fixed and static entities associated with specific geographical and communicative settings. The violation of these expectations works at the expense of nonstandard styles and corresponds to the breach of linguistic homogeneity and monolingualism. Needless to say, more research is required along these lines so as to bring to the surface more metapragmatic stereotypes on stylistic resources and use in the Greek linguocultural community, as well as to compare with relevant findings from other communities.

Finally, I would like to underline the fact that such stereotypes usually go unnoticed in mass culture texts and may even become naturalised, as linguistic behaviours breaching or deviating from them are usually framed in a "trivial" and "non-serious" manner: that is, they are humorously stigmatised. Scrutinising the perceived stylistic incongruities in humorous mass culture texts could enable the audience to reflect on what they consider "appropriate" and "inappropriate" linguistic behaviour, and thus, become critically aware of the impact of metapragmatic stereotypes on the evaluation of speakers and their styles.

\section{Acknowledgments}

The present study was conducted in the context of the Operational Programme "Education and Lifelong Learning" and has been co-funded by the EU (European Social Fund) and national resources. In particular, it was part of the Greek research project Thalis (2011-2015), entitled: "Linguistic variation and language ideologies in mass cultural texts: Design, development and 
assessment of learning material for critical language awareness" (Ministry of Education and Religious Affairs, Funding ID: MIS 375599). The author would like to thank Kyriakoula Tzortzatou and Nikoletta Panagaki for useful comments and suggestions on this paper, as well as Konstantinos Louzis for his support in the statistical tests.

\section{References}

Agha, A. (1998). 'Stereotypes and registers in honorific language'. Language in Society 27 (2), pp. 151-193.

Agha, A. (2004). 'Registers of language', in Duranti, A. (ed.), A Companion to Linguistic Anthropology, Oxford: Blackwell, pp. 23-45.

Agha, A. (2007). Language and Social Relations. Cambridge: Cambridge University Press.

Antonopoulou, E. (2004). 'Humour theory and translation research: Proper names in humorous discourse'. Humor: International Journal of Humor Research 17 (3), pp. 219-255.

Apter, M. (1982). The Experience of Motivation: The Theory of Psychological Reversals. Cambridge: Academic Press.

Archakis, A., Lampropoulou, S., Tsakona, V. \& Tsami, V. (2014). 'Linguistic varieties in style: Humorous representation in Greek mass culture texts'. Discourse, Context \& Media 3 (1), pp. 46-55.

Archakis, A., Lampropoulou, S., Tsakona, V. \& Tsami, V. (2015). 'Style and humour in Greek mass culture texts', in Brzozowska, D. \& Chłopicki, W. (eds.), Culture's Software: Communication Styles. Cambridge: Cambridge Scholars Publishing, pp. 16-38.

Archakis, A. \& Tsakona, V. (2005). 'Analysing conversational data in GTVH terms: A new approach to the issue of identity construction via humour'. Humor: International Journal of Humor Research 18 (1), pp. 41-68.

Archakis, A. \& Tsakona, V. (2006). 'Script oppositions and humorous targets: Promoting values and constructing identities via humour in Greek conversational data'. Stylistica XV, pp. 119134.

Archakis, A. \& Tsakona, V. (2011). The Narrative Construction of Identities in Critical Education. Basingstoke: Palgrave Macmillan.

Attardo, S. (1994). Linguistic Theories of Humour. Berlin: Mouton de Gruyter.

Attardo, S. (2001). Humorous Texts: A Semantic and Pragmatic Analysis. Berlin and New York: Mouton de Gruyter.

Attardo, S. (2009). 'A commentary on Antonopoulou and Nikiforidou', in Brône, G. \& Vandaele, J. (eds.), Cognitive Poetics. Goals, Gains and Gaps. Berlin and New York: Mouton de Gruyter, pp. 315-317.

Bainschab-Damaris, A. C. (2009). The Humour of Christopher Moore. MA thesis, Universität Wien. Retrieved April 24, 2019 from http://othes.univie.ac.at/3440/1/2009-0118_0201010.pdf.

Bergen, D. (2018). 'Humor as a developmental phenomenon: the contributions of Paul McGhee'. Humor - International Journal of Humor Research 31 (2), pp. 1-19.

Berglin, I. T. (2009). ' 'Really? You're gonna say “tunes”?': The functions of register clashes in the television drama series Gilmore Girls.' Unpublished essay, Mälardalen University. Retrieved April 24, 2019 from portal.org/smash/get/diva2:345243/FULLTEXT01.pdf.

Billig, M. (2005). Laughter and Ridicule. Towards a Social Critique of Humor. London: Sage.

Blommaert, J. \& Rampton, B. (2011). 'Language and superdiversity'. Diversities 13 (2), pp. 120. 
Busch, B. (2012). 'The linguistic repertoire revisited'. Applied Linguistics 33, pp. 503-523.

Canestrati, C., Branchini, E., Bianchi, I., Savardi, U. \& Burro, R. (2018). 'Pleasures of the mind: What makes jokes and insight problems enjoyable'. Frontiers in Psychology 8 (2297), pp. 121.

Coupland, N. (2007). Style: Language Variation and Identity. Cambridge: Cambridge University Press.

Canakis, K. (1994). 'Diglossia as an agent of humour in the writings of Elena Akrita'. Journal of Modern Greek Studies 12, pp. 221-37.

Eckert, P. (2012 eds.). 'Three waves of variation study: The emergence of meaning in the study of sociolinguistic variation'. Annual Review of Anthropology 41, pp. 87-100.

Eckert, P. \& Rickford, J, R. (2002). Style and Sociolinguistic Variation. Cambridge: Cambridge University Press.

El Refaie, E. (2011). 'The pragmatics of humour reception: Young people's responses to a newspaper cartoon'. Humor: International Journal of Humor Research 24 (1), pp. 87-108.

Gardner, S. (2010). 'Discourse shifting for humorous effect: The python method'. Bulletin of Graduate School of Education Okayama University 145, pp. 39-46.

Georgakopoulou, A. (2000). 'On the sociolinguistics of popular films: Funny characters, funny voices'. Journal of Modern Greek Studies 18 (1), pp. 119-133.

Heller, M. (2007). 'Bilingualism as ideology and practice', in Heller, M. (ed.), Bilingualism: A Social Approach. Basingstoke, Hampshire \& New York: Palgrave Macmillan, pp, 1-21.

Hiramoto, M. (2011). 'Is dat dog you're eating?: Mock Philipino, Hawai'i Creole, and local elitism'. Pragmatics 21, pp. 341-71.

Hudson, R. A. (1996). Sociolinguistics. Cambridge: Cambridge University Press.

I bar my heart Kitsos and Tasoula Vodafone new. 2012. https://www.youtube.com/watch?v=SNHC2n72wZI [in Greek].

Irvine T. J. (2001). ' 'Style' as distinctiveness: the culture and ideology of linguistic differentiation', in Eckert, P. \& Rickford, R. J. (eds.), Style and Sociolinguistic Variation. Cambridge: Cambridge University Press, pp. 21-43.

Johnson, S. \& Ensslin, A. (2007). 'Language in the media: Theory and practice', in Johnson, A. \& Ensslin, A. (eds.), Language in the Media. Continuum: London, pp. 3-22.

Johnstone, B. (2009). 'Pittsburghese shirts: Commodification and the enregisterment of an urban dialect'. American Speech 84, pp. 157-175.

Jørgensen, N. J. \& Juffermans, K. (2011). 'Superdiversity'. Retrieved June 10, 2013 from http://www.academia.edu/1808420/Superdiversity.html.

Kubovy, M. (1999). 'On the pleasures of the mind', in Kahneman, D., Diener, E. \& Schwarz, N. (eds.), Well-Being: Foundations of Hedonic Psychology. New York: Russell Sage Foundation, pp. 134-154.

Liakos, A. (2005). How Did Those who Wanted to Change the World Imagine the Nation? Athens: Polis [in Greek].

McGhee, P. (2018). 'Some reflections'. Humor: International Journal of Humor Research 31 (2), pp. 401-404.

Moody, A. (2013). 'Language ideology in the discourse of popular culture', in Chapelle, C. A. (ed.), The Encyclopedia of Applied Linguistics. Oxford: Blackwell. Retrieved June 10, 2013 from http://onlinelibrary.wiley.com/store/10.1002/9781405198431/asset/homepages/ 5_Language_Ideology_in the Discourse_of_Popular_Culture.pdf?v=1\&s=8344a7b91a20 ceea92a0ed6fe0aaa4eda66f7037.html.

Piata, A. (2019). 'Stylistic humor across modalities: The case of Classical Art Memes'. Internet Pragmatics 2 (1), pp. 1-28. 
Rampton, B. (1995). Crossing: Language and Ethnicity among Adolescents. London and New York: Longman.

Rampton, B. (2006). Language in Late Modernity: Interaction in an Urban School. Cambridge: Cambridge University Press.

Raskin, V. 1985. Semantic Mechanisms of Humor. Dordrecht: D. Reidel.

Simpson, P. (2003). On the Discourse of Satire. Towards a Stylistic Model of Satirical Humour. Amsterdam: John Benjamins.

Stamou, A. G. (2011). 'Speech style and the construction of social division: Evidence from Greek television'. Language \& Communication 31 (4), pp. 329-344.

Stamou, A. G. (2012a). 'Representations of sociolinguistic reality in popular culture: Analytical framework for the development of critical language awareness'. Glossologia 20, pp. 19-38 [in Greek].

Stamou, A. G. (2012b). 'Representations of linguistic variation in children's books: Register stylization as a resource for (critical) language awareness'. Language Awareness 21 (4), pp. 313-29.

Stuart-Smith, J. (2006). 'The influence of the media', in Llamas, C., Mullany, L. \& Stockwell, P. (eds.), The Routledge Companion to Sociolinguistics. London and New York: Routledge, pp. 140-148.

Tsakona, V. (2004). 'Humor in written narratives: A linguistic approach'. Unpublished $\mathrm{PhD}$ thesis, University of Athens. Retrieved February 25, 2019 from http://thesis.ekt.gr/content/index.jsp?id=17786\&lang=el. [in Greek].

Tsakona, V. (2013). The Sociolinguistics of Humor: Theory, Functions and Teaching. Athens: Grigoris [in Greek].

Tsami, V. (2018). 'Mass culture texts and language variation: Critical discourse analysis and assessment of learning material'. Unpublished doctoral dissertation, University of Patras [in Greek].

Tsami, V., Archakis, A., Lampropoulou, S. \& Tsakona, V. (2014). 'The representation of linguistic variation in TV mass culture texts', in Kotzoglou G., Nikolou, K., Karantzola, E., Frantzi, K., Galantomos, I., Georgalidou, M., Kourti-Kazoullis, V., Papadopoulou, Ch. \& Vlachou, E. (eds.), Selected Papers of the $11^{\text {th }}$ International Conference on Greek Linguistics. University of the Aegean, Rhodes, Greece, 27-29 September 2013, pp. 17161729 [in Greek].

Van den Bulck, H. (2001). 'Public service television and national identity as a project of modernity: The example of flemish television.' Media, Culture \& Society 23, pp. 53-69.

Wyer, S. R. \& Collins, E. J. (1992). 'A theory of humor elicitation.' Psychological Review 99 (4), pp. 663-688

Xydopoulos, J. G., Tzortzatou, K. \& Archakis, A. in press. 'The perception of Greek national orthography and Greeklish at the threshold of the post-modern era: Investigating attitudes towards orthography in Greek education'. Journal of Modern Greek Studies. 